\title{
Reflejos de la Segunda Guerra Mundial en la novela utópica española: Los días están contados (1944), de Cecilio Benítez de Castro
}

\author{
Mariano MARTÍN RodRÍGUEZ \\ Centrul de Cercetări Literare şi Enciclopedice (Cluj-Napoca) \\ martioa@hotmail.com
}

\begin{abstract}
RESUMEN
Al terminar la Guerra Civil española en 1939, la literatura reanudó su curso anterior, al menos en algunas de sus modalidades, como la llamada novela utópica. Uno de los primeros ejemplos de la posguerra fue un libro bellamente escrito que reflejó, en forma de parábola especulativa, el conflicto coetáneo. Se trata de Los días están contados (1944), de Cecilio Benítez de Castro, una novela en la que se suceden una historia de violencia atroz en el marco de una sociedad primitiva aislada en los Pirineos franceses y la narración de una guerra total en otro planeta. Esta refleja la contienda que se estaba librando entonces en la Tierra, de manera que queda subrayada la crueldad bélica como característica inherente de los seres pensantes, desde una perspectiva claramente pacifista que hace hincapié en la trágica dimensión universal de la violencia, en el tiempo y en el espacio.
\end{abstract}

Palabras clave: novela utópica, Segunda Guerra Mundial, Benítez de Castro, pacifismo.

\section{Reflections of World War II in the Spanish utopian novel: Los dias están contados (1944), by Cecilio Benitez de Castro}

\begin{abstract}
After the end of the Spanish Civil War in 1939, literature resumed its previous course, at least in some of its modes, such as the scientific romance. One of its first examples in the postwar period is a beautifully written book that reflected, in form of a speculative parable, the contemporary conflict. This is Cecilio Benítez de Castro's Los días están contados (1944), a novel in which a story of a total war on another planet follows another story of appalling violence that takes place within a primitive society isolated in the French Pyrenees, both reflecting the conflict then raging on Earth. Warlike cruelty as an inherent feature of sentient beings is thus underlined from a clearly pacifist perspective that emphasizes the tragic universal dimension of violence, in time and in space.
\end{abstract}

Keywords: utopian novel, World War II, Benítez de Castro, pacifism. 
Entre las numerosas leyendas que siguen afectando a la visión históricamente imparcial de la Guerra Civil española de 1936-1939 y la subsiguiente posguerra (hasta el fin del aislamiento del régimen franquista en 1953) se cuentan las creencias infundadas de que tal contienda civil supuso un corte cultural neto y de que España permaneció aislada por el conflicto y la represión posterior, incluida la censura, respecto a las grandes inquietudes internacionales del momento. Sin embargo, existen manifestaciones literarias que lo desmienten, tales como la narrativa utópica. Quizás mejor que otras, esta modalidad ficcional puede ilustrar que, tras el hiato de la Guerra Civil, la España de la posguerra no sufrió un corte literario radical. Antes y después de esa contienda, hubo escritores que concibieron su obra desde una perspectiva universalista. Por ejemplo, algunos se preocuparon por el destino del ser humano en una sociedad crecientemente tecnológica y por las posibles consecuencias políticas que podría acarrear el nuevo orden técnico. Son estas consecuencias las que se abordaron en varios libros españoles que, durante este período, se ocuparon de esta cuestión recurriendo a procedimientos especulativos dotados de una significación alegórica más o menos clara. Su repaso podría contribuir tal vez a sugerir que la Guerra Civil española fue, culturalmente, un trágico intermedio más que una línea divisoria neta, al menos a este respecto.

El primer tercio del siglo XX fue en España una época de auge relativo de la ficción utópica (Martín Rodríguez 2014), tal como se solían designar entonces las obras en las que se presentara una sociedad alternativa a la contemporánea y a menudo futura o, al menos, ajena a las terrestres conocidas ${ }^{1}$. Después de la Guerra Civil, esta denominación se mantuvo para obras semejantes, del tipo consagrado por las anticipaciones novelísticas de H. G. Wells, que en inglés se denominaban scientific romances. Así es como denominó Eugenio de Nora, por ejemplo, scientific romances no necesariamente utópicos como La verdad en la ilusión (1912), de Luis Antón del Olmet («intensa ficción utópica»; Nora 1963: 380) o El archipiélago maravilloso (1923), de Luis Araquistáin («una de las raras novelas utópicas de nuestra literatura»; Nora 1968: 78). Este crítico aplicó una clave de lectura análoga a obras de la misma modalidad publicadas después de 1939, tales como La bomba increíble (1950), del exiliado Pedro Salinas, que «combina originalmente la anticipación utópica [...] con la pura fantasía» en una «novela de «anticipación», sobre base más o menos sociológico-científica [...] casi desconocida entre nosotros» (1968: 221). Sin embargo, este desconocimiento era más bien del propio estudioso, porque La bomba increíble solo es la manifestación más reputada de la novela utópica de la posguerra española, distando de ser la única. Su tema y planteamiento cosmopolitas, además de su hincapié en el orden socio-político desde un punto de vista

${ }^{1}$ La expresión preferida para designar lo que hoy se llamaría ciencia ficción parece haber sido la de «novela utópica», con su variante de «novela de la utopía», de acuerdo con la tendencia de entonces de englobar toda la literatura especulativa en el universo de la utopía, de acuerdo con la concepción de esta definida como sigue en esa misma época: «Une utopie est la description d'un monde imaginaire, en dehors de notre espace ou de notre temps, ou en tout cas, de l'espace et du temps historiques et géographiques. C'est la description d'un monde constitué sur des principes différents de ceux qui sont à l'œuvre dans le monde réel» (Ruyer 1950: 3). 
crítico, coinciden más bien con varias obras publicadas dentro de España antes de 1953. Tras la novela corta satírica y distópica de Emilio Carrere La momia de Rebeque (1941), se podría recordar la miscelánea de ensayos especulativos ${ }^{2}$ y relatos ambientados en el futuro Bajo las constelaciones (Viajes de Gil del Mar) (1943), de Carlos Buigas, que constituye una serie excepcional por recordar la producción propiamente dicha de la llamada Golden Age coetánea (Clifford D. Simak, Isaac Asimov, etc.) de la ciencia ficción estadounidense, en contraste con la modalidad utópica aún hegemónica en Europa y en España, ilustrada por ficciones apocalípticas como el cuento «Arca número dos» (1950), de José Luis Sampedro, o el drama Como era en un principio (1951), de Jorge y José de la Cueva, y distopías como «Futurama» (Antología de los Borrases, 1950), de Tomás Borrás, que parece el equivalente español en espíritu y forma de la distopía clásica de Zamiatin, aunque la dimensión política pasa en el español a un segundo plano, al centrarse la narración en una alienación muy contemporánea derivada del uso de narcóticos con fines recreativos y de satisfacción emocional. A esta narración sobresaliente de Borrás se puede sumar Marea verde (1951), de Jaime de Foxá, otra interesante anticipación distópica, igualmente demasiado poco conocida, que es también una hábil y bien escrita denuncia del populismo contra la manipulación humana (un producto convierte la sangre en savia, de manera que las personas procesan la luz como las plantas y acaban adquiriendo las características de pasividad de estas) y social (el producto se destina únicamente a las masas). Estas dos distopías pueden flanquear honrosamente a La bomba increíble como muestras destacadas del género en España. Con todo, es otra la novela española de la posguerra que, dentro del género utópico, anuncia en mayor medida el planteamiento pacifista y escéptico frente a la tecnología adoptado por Salinas en su obra maestra narrativa. Se trata de Los días están contados (1944), de Cecilio Benítez de Castro, la cual se inscribe a su vez en una tradición de narrativa sobre guerras especulativas que Salinas recoge como posibilidad terrible en la era atómica, aunque no llegó a atreverse a detonar su bomba increible y mostrar sus efectos materialmente destructivos. Benítez de Castro, por su parte, llevó a sus consecuencias finales el motivo temático de la guerra apocalíptica en su novela.

El mismo Wells había renovado el añejo tema ficcional de la guerra futura (Clarke 1966) en The War in the Air (1908) y en The World Set Free (1914) al reemplazar el enfoque geopolítico nacionalista por otro mundial centrado en la destrucción masiva y en la amenaza que representaba la guerra para la misma supervivencia de la humanidad. Tras las masacres industrializadas de la Primera Guerra Mundial, esta preocupación adquirió mayor protagonismo en la ficción utópica moderna y fueron legión los scientific romances que ofrecieron panoramas apocalípticos tras una nueva contienda planetaria, tan temida como tenida cada vez más por inexorable. La película Things to Come (1936), dirigida por William Cameron Menzies sobre guion de Wells, indica que tal topos literario era ya tan común en los años treinta del pasa-

\footnotetext{
${ }^{2}$ Una suerte de ensayo especulativo ficcional del tipo cultivado por Buigas es también «La metamorfosis de los microbios» (Foehn, 1948), de Mercedes Salisachs.
} 
do siglo que hasta se había traspasado a un arte popular como el cine. Quizá debido a su neutralidad en la Gran Guerra y a su apartamiento voluntario del tablero geopolítico europeo, el tema del apocalipsis bélico futuro no fue muy tratado en España, aunque conviene mencionar una novela también injustamente olvidada, Después del gas (1935), de David Arias. Esta es «una narración que destaca por su agilidad y buen sentido del ritmo y de la intriga al contar una guerra del futuro próximo que se prolonga hasta el derrumbamiento completo de la civilización, mientras el inventor del destructivo gas profusamente utilizado en la lucha observa horrorizado desde su búnker el ocaso del hombre» (Martín Rodríguez 2014: 29-30). Aunque su final es optimista, porque la violencia desatada permitirá una especie de purificación ética de la humanidad y dará pie a un nuevo orden eutópico, la novela de Arias destaca sobre todo por el espectáculo horrible y sublime a la vez del derrumbe biológico y social de la humanidad, enfrentada a sí misma sin cuartel. Primero la Guerra Civil española y luego la Segunda Guerra Mundial a una escala mucho mayor, no hicieron sino confirmar los temores de Wells y Arias, aunque sin el resultado consolador representado por la utopía realizada.

El planteamiento pacifista de Después del gas lo retomó Los días están contados, que se puede entender como una reacción ante la guerra total que se estaba practicando por entonces, con bombardeos masivos de ciudades y la consideración de la población civil como objetivo militar, mediante una historia que pone entre paréntesis las razones y circunstancias concretas de esa y cualquier guerra para señalar sus causas profundas en la humanidad misma, más allá incluso de la consideración frecuente de la tecnología como condición necesaria para las modernas masacres industrializadas. Así refutó Benítez de Castro su encasillamiento como autor guerracivilista en favor del bando faccioso que le ha reportado su novela quizá más famosa, Se ha conquistado el kilómetro 6... (1939), una exaltación del ejército franquista por la que es sobre todo recordado todavía (Campal Fernández 2005; Martínez Cachero 2009: 279-280; Ripoll Sintes 2013), pese a que el autor renegó de ella, queriendo retirarla de su catálogo, según testimonio de unos críticos académicos norteamericanos coetáneos ${ }^{3}$. Sin embargo, el éxito de público de esta novela tendenciosa no impidió a los críticos académicos de su tiempo señalar el mayor mérito de sus novelas fantásticas, pues Valbuena Prat (1968) dedicó gran espacio a dos de ellas en su Historia de la literatura española, a saber, La rebelión de los personajes (1940) y El creador (1940), reconociendo en ambas el interés de sus tramas fantásticas y de su estructura decididamente moderna. Está claro que merecerían mayor atención y, de hecho, alguna han recibido recientemente (Ripoll Sintes 2013), pero es quizás Los días están contados la que destaca en el plano español, e incluso europeo, al menos en su género, como se reconoció fuera de España:

3 «[...] Se ha ocupado el kilómetro 6, que apareció en 1939, puede considerarse la primera novela de la generación actual. Esta novela, que lleva el subtítulo «Contestación a Remarque», es de carácter tendencioso. Aunque tuvo gran éxito, el autor nos escribió recientemente que, por no pertenecer al ciclo literario que le interesa cultivar, quisiera borrarla de su catálogo» (Ornstein y Causey 1951: 128). 
En Los días están contados se utiliza el tema wellsiano del «hombre de Marte». Esta novela, que es una de las mejores de Benítez, presenta el ascenso y caída de una sociedad imaginaria, concluyendo que la única salvación para nuestra civilización estriba en el ejercicio del amor fraternal y de los ideales cristianos. (Ornstein y Causey 1951: 128).

La última observación puede desorientar. Aunque se mencione a Dios como garante moral de una ética que podría impedir que los seres inteligentes se maten unos a otros, así como de ese «amor fraternal» salvífico, la novela ni es confesional ni ensalza los valores cristianos, sino más bien un humanismo laico en cuya configuración Dios no ocupa ni mucho menos un lugar central. Por lo demás, el cristianismo significaría una promesa de redención, aunque sea en una dimensión ultraterrena, y esta promesa brilla por su ausencia en Los días están contados. La violencia como origen y destino ineluctable es lo que parece animar los diferentes mundos imaginarios presentados en la novela, en la que las alusiones religiosas no pasan de las palabras a los actos en las humanidades terrestres y extraterrestres. Ni siquiera podrían hacerlo, porque la violencia tiene un carácter esencial. El ser pensante no es bueno por naturaleza.

Como una refutación práctica de la parábola del buen salvaje, Benítez de Castro recurre en la primera parte de Los días están contados a un género especulativo de gran éxito desde el inicio de la gran ola imperialista occidental en el siglo XIX, la ficción sobre mundos perdidos. Esta había experimentado en la década de 1930 una mutación en un sentido utópico opuesto a la tendencia imperialista anterior. La sociedad encontrada ya no solía ser una civilización decadente y opulenta a la espera de la modernización capitalista encarnada por el héroe, sino una comunidad a menudo primitiva desde el punto de vista tecnológico, aunque dotada de unos valores éticos y espirituales muy superiores a los de las sociedades colonizadoras. El ejemplo más conocido probablemente de esta clase de ficción es una novela inglesa de influencia incalculable, Lost Horizon (1933), de James Hilton, en la que se presentaba un valle aislado con todos los atractivos de lo utópico y hasta de lo paradisíaco. En tal edén cerrado debían preservarse las grandes conquistas estéticas e intelectuales de una civilización sometida a la amenaza inminente de una guerra aún más total y destructiva que la primera mundial. No obstante, la población no era primitiva, porque los avances tecno-científicos también se atesorarían en el valle protector para el futuro. En cambio, una novela de la misma modalidad contemporánea al proceso bélico europeo iniciado en España en 1936 negó cualquier validez a la civilización moderna. En La Vallée perdue (1939), de Noëlle Roger, se imagina la pervivencia en medio de los Alpes suizos de una población neolítica celosa de su forma de vida. La llegada por aire de unos parisinos al valle desencadena un proceso que pone en peligro la supervivencia de la sociedad primitiva, pero el mundo perdido consigue permanecer inviolado. En mayor medida aún que en Lost Horizon, el primitivismo de la sociedad perdida es una elección consciente y Roger da a entender que esa sociedad es mejor que la contemporánea, violenta y materialista. En cambio, Benítez de Castro rechaza la posibilidad de una humanidad primitiva exenta de los males del hombre moderno al presentar, en el corazón de los Pirineos fran- 
ceses, una comunidad análoga a la idealizada por Roger, con la que el protagonistaexplorador y víctima entra pronto en contacto violento.

El héroe sufriente de la historia es Alberto Brian, un profesor de la Sorbona que se entera por un amigo científico de la posibilidad de que los restos meteoríticos de un planeta estallado en el sistema de Alfa Centauri hubieran caído en esa cadena montañosa y asume la tarea de ir a investigarlos. Tras abandonar la civilización en una aldea de pocas casas, se adentra en un valle apenas frecuentado llamado gráficamente Infierno. En este vive una población de pastores sin apenas contacto con el exterior, cuyo nivel tecnológico parece equivalente al del Neolítico. Los nombres de sus habitantes no tienen que ver con las lenguas románicas de la zona, ni tampoco con el vasco, lo que acentúa el efecto de extrañamiento exótico cifrado en encontrarse tal pueblo en medio de Europa. El profesor francés conoce en primer lugar a una adolescente, Leila, que lo adopta y desea como pareja, sobre todo para escapar a la brutalidad de Samo, el macho alfa de los pastores, que desea adquirirla al padre de ella, Bepo. Las relaciones sociales obedecen a un régimen patriarcal estricto. La intrusión del profesor desencadena rápidamente la tragedia. Aunque no tiene interés erótico alguno por la chica, Samo pronto lo considera un rival al que eliminar, primero por las buenas, y luego, cuando Leila impone su presencia y sentimientos al reticente civilizado, por las malas: Bepo, Samo y sus pastores les dan caza y, en su huida, Alberto y Leila caen en la sima creada por el meteorito celeste. En el epílogo, nos enteramos de que, al salir, la joven había perdido el equilibrio y provocado un alud que había sepultado la sima y su contenido, mientras que el profesor apenas había podido escapar con vida y regresar a París. Está claro en la novela que el primitivismo no es óbice para el desencadenamiento de instintos de posesión y dominio, que se traducen en el conflicto con quien parecía amenazar la posición del macho dominante. Benítez de Castro da la vuelta así al viejo topos de la pastoral idealizada, de la nostalgia de un supuesto paraíso pretecnológico ensalzado por Roger, igual que haría años más tarde Alejo Carpentier en Los pasos perdidos (1952). La solución al belicismo no vendría, pues, de una ilusoria vuelta al pasado, tal como se reitera en las dos partes extraterrestres de la novela de Benítez de Castro.

Dentro de la sima, Brian descubre un cadáver de apariencia humana, de aspecto no muy distinto al de los pastores del valle. El cuerpo llevaba un tubo con un escrito en una especie de latín fruto de una evolución paralela en la Tierra y en el planeta del que procedía el bólido ${ }^{4}$. Así pudo leer lo que constituye la segunda parte del libro, el «Diario de Hachos Regila... en la tribu de los fagos...». Este diario es en

${ }^{4}$ La convergencia evolutiva explicaría, para el autor, el hecho de que las humanidades de la Tierra y del planeta sin nombre de Alfa Centauri sean prácticamente iguales, incluso lingüísticamente. Por lo demás, la presentación de los extraterrestres como humanidades parecidas o iguales a la terrestre tiene una larga tradición en la ficción utópica y científica, tal vez para facilitar la correspondencia alegórica entre los mundos posibles respectivos. Así ocurre, por ejemplo, en Star ou $\Psi$ de Cassiopée: Histoire merveilleuse de l'un des mondes de l'espace, nature singulière, coutumes, voyages, littérature starienne, poëmes et comédies traduits du starien (1854), de Charlemagne Ischir Defontenay, consistente en una serie de documentos procedentes del sistema planetario de esa estrella que habrían caído a la Tierra, de forma parecida a la hipótesis especulativa de Los días están contados. 
realidad una narración homodiegética escrita por Silas Regila, el bisabuelo del transmisor del manuscrito, y adopta el discurso novelístico usual, salvo unas páginas (1944: 124-126) en que sí se adopta la retórica del diario (segmentación por fechas y narración de los hechos en presente de indicativo, sobre todo). No obstante, la perspectiva adoptada es la del narrador protagonista frente a los sucesos de su vida y del mundo. Ingeniero, ha sido destinado a una región ultraperiférica y con población negra colonizada por su país, Isinia. En ella se encuentran las minas Eugas, el principal recurso natural y verdadera base del desarrollo y la capacidad de esfuerzo bélico de la potencia colonizadora. Las minas están dirigidas con manos de hierro por Milos Drida, una figura carismática que es responsable en gran parte del empuje tecnológico y geopolítico de la metrópoli. Esta no tarda en enfrentarse a Omenia, la potencia rival. La guerra se prolonga durante bastante tiempo, puesto que ambos países están equilibrados en sus fuerzas, con todo el cortejo consecuente de destrucciones y, en especial, el desarrollo de la lógica bélica como un mecanismo autoalimentado $^{5}$. A los países contendientes originales se irán sumando otros con el mismo propósito de utilizar el supremo argumento de la fuerza para imponer «el derecho a imperar sobre el orbe» (1944: 120), basado en un imperialismo descarado en el que los argumentos raciales y socialdarwinistas solo eran justificaciones $a d$ hoc del propio afán de dominación. Según Milos Drida:

No había civilización, a su juicio, si esta no podía sojuzgar a la civilización vecina. Estaba convencido al mismo tiempo de que no existen una civilización o un progreso generales, sino varios y varios simultáneos, según las facultades y las dotes de cada raza propulsora. Si Isinia ganaba la guerra, se serviría de los vencidos para sus fines, en calidad de raza superior, y si la perdía, estos se servirían de ella por el mismo motivo. ¿No estaba patente, acaso, la ley, en los hombres de la raza negra, que cargaban los vagones en las minas? Si ellos tuvieran suficiente talento, serían los blancos quienes los cargarían. (1944: 114)

Ahí se resumen, de manera gráficamente brutal, los argumentos que, desde las justificaciones racistas del colonialismo hasta el análisis de desarrollo independiente de las civilizaciones defendido en la época por el muy influyente Oswald Spengler, estaban invocándose en Europa para justificar tanto el expansionismo nazi como la explotación colonial y racista practicada desde hacía décadas por varios de sus enemigos aliados. Al mismo tiempo, otras nuevas potencias iban entrando en guerra y sumándose al proceso expansionista desencadenado tanto en el mundo real de la Segunda Guerra Mundial como en su reflejo imaginario del planeta de Alfa Centauri. Allí también habrían aprovechado otros países la debilidad de los primeros contendientes a causa del conflicto para promover sus intereses económicos y territoriales y sumarse al festín imperialista. Benítez de Castro pone entre paréntesis las justificaciones oficiales de la Segunda Guerra Mundial

5 «La vieja rivalidad entre mi país y Omenia, que fue el primer paso, resultaba un problema insignificante. Al segundo año ya no interesaba. [...] en el tercer año [...] nadie recordaba el primitivo problema de Omenia e Isinia» (1944: 120). 
para denunciar con mayor eficacia su carácter de pulso geopolítico en busca de la hegemonía planetaria. Fuera de esta correspondencia alegórica general, el autor se guarda mucho de establecer equivalencias directas entre las potencias extraterrestres y las terrestres, pues en la descripción de cada una se aprecian rasgos tanto de Alemania como de Gran Bretaña. Tampoco las potencias sumadas aparecen como reflejos de los Estados Unidos o la Unión Soviética. No se sugiere que existan diferencias fundamentales en sus ordenamientos sociopolíticos, pues lo pertinente no es la ideología, sino el desarrollo industrial que posibilita el enfrentamiento a gran escala por la dominación. La ideología ni aparece, porque no se trata de hacer propaganda de ideas, sino de mostrar, al desnudo, los efectos del instinto territorial en el ser humano. Y estos efectos son terribles, pues pronto se utiliza en la guerra un arsenal químico que acaba destruyéndolo todo. Tan solo las minas Eugas se salvan. Ante tal espectáculo, el mismo Milos Drida experimenta una conversión:

Todos nos hemos equivocado. Creíamos que podríamos manejar desde el Estado el movimiento de la Historia. La verdad era que el odio no estaba en los Estados, sino en los pueblos. [...] No se aspira a gobernar, sino a destruir al vencido. No se aspira sino a disfrutar desierta la redondez de la tierra... [...] Hemos construido poderosas máquinas que hubieran labrado nuestra dicha. Pero las hemos aguzado para que nos destruyeran. Hoy, en manos de los más rabiosos, son inexorables. (1944: 123)

Este discurso estaba más que justificado en aquel momento, cuando la Segunda Guerra Mundial hacía tiempo que se había convertido en total y ya se presentía la invención de un arma que significaba la posibilidad de llevar a sus últimas consecuencias la expresión de odio, del que las luchas entre naciones e ideologías no eran sino sus manifestaciones anecdóticas. A este respecto, cabe recordar que Pedro Salinas publicó también en 1944 su poema «Cero», en el que se describen los efectos de una bomba apocalíptica que se parece ominosamente a la atómica aún no conocida entonces. Ante aquel odio, Milos Drida solo ve la solución de la renuncia a la tecnología, por ser inevitablemente destructora. En Francia, René Barjavel había defendido un año antes, en Ravage (1943), una solución parecida tras una catástrofe mundial causada por la ficticia desaparición de la electricidad, pues el héroe protagonista escapaba con otros supervivientes a las destrucciones y creaba en un valle una sociedad libre de tecnología moderna, aplicando incluso la pena de muerte a un joven inventor. Milos Drida adopta un papel semejante en la novela de Benítez de Castro, aunque sin el cariz dictatorial del patriarca de Barjavel. Tras dirigir la expedición, birracial e igualitaria entre negros y blancos reunidos en una sola humanidad restante y sufriente ante la completa desolación del mundo, su legado es el de convencer a los cuatro ingenieros, a quienes ha confiado al pueblo repartido entre los cuatro puntos cardinales, de que reconozcan el fracaso de la primera prueba de la Humanidad e intenten un nuevo inicio. La tecnología, que habría podido servir «para comunicar unos continentes con otros y esparcir la cultura de las razas más adelantadas entre las más míseras», para adelantar el conocimiento y para «aliviar dolores» (1944: 143), se había utilizado «para arrasar ciudades, para destruir pueblos, para remover la tierra y arar sepulturas desde los cielos» (1944: 143). Además, 
se gastaba en bombas los recursos necesarios para acabar con la pobreza. Por ello, el nuevo comienzo sería sin trabajo de los metales, sin construcciones en piedra que pudieran convertirse en fortalezas y también sin la escritura difusora de ideologías. De esta manera, los descendientes vivirían en un mundo en el que nada los distraería de su curso natural, de vivir simplemente su vida. Únicamente un descendiente por tribu recibiría el testimonio de la Historia y sabría que, de fallar la nueva sociedad neoprimitiva, los cuatro representantes deberían reunirse en el lugar de su juramento, cuyo tenor conoceremos al cabo de la tercera parte, escrita por Hachos Regila como continuación de la de su antepasado.

Este testimonio expone una intriga trágica cuyo desarrollo es paralelo a la de la primera parte de la novela. Al principio, parece que los sueños del Milos Drila converso al pacifismo se han cumplido. Los descendientes viven en aldeas de aspecto igualmente neolítico, dedicados a la agricultura y a la ganadería, y sujetos a los caprichos del tiempo atmosférico. En este contexto precario y difícil, basta el hecho de que uno de ellos se deje dominar por sus instintos para que la sociedad entera se derrumbe. El drama se produce, como en la primera parte, por causas pasionales. Almo, uno de los jóvenes, desea la mujer de otro y no duda en matar a este último y en raptar a la mujer, que se suicida antes de que se apodere completamente de ella. Así se pone en marcha una vez más la espiral de la violencia, porque los parientes de las víctimas desean vengarse de su asesino, mientras que el resto de la aldea intuye que la paz ha terminado. Hachos Regila, el joven depositario de la Historia, intenta disuadir a Almo de seguir por ese camino, contándole lo ocurrido a la civilización del planeta, pero no consigue sino que el otro se entere de que existe otra vía de existencia, cifrada en la imposición violenta de la propia voluntad a los otros, que quedarían a su servicio. Almo idea entonces cómo hacer armas y se aprovecha de su superioridad tecnológica para atacar, atraerse a otros descontentos y ambiciosos y esclavizar a sus paisanos. Estos, que habían pensado inicialmente en excluir simplemente al criminal de su comunidad, se ven obligados a levantar vallas y a fabricar también armas para defenderse. Una vez iniciada esta espiral, ya no hay vuelta atrás. Hachos Regila y otros de la tribu deciden dar la noticia en parejas a las otras tres tribus y reunirse en el lugar prescrito.

El viaje está preñado de presentimientos oscuros, que se expresan mediante una escritura mesuradamente poética ${ }^{6}$. Una vez más, el espectáculo de las ruinas de la antigua civilización introduce un doloroso sentido de pérdida, junto a lo sublime del terror ante la destrucción, de los «testigos apagados de la catástrofe lejana» (1944: 215), sobre todo de la antigua capital. En estas páginas, la estética de las ruinas se renueva mediante imágenes en que se confrontan la grandiosidad de la civilización

${ }^{6}$ Por ejemplo: «No sé qué fuerza grave nos impulsaba, pero caminábamos a través de inmensos páramos, de larguísimos desiertos, de espesísimas selvas, como si una voluntad poderosa y secreta nos moviera, de sol a sol, mientras nuestros cuerpos se afianzaban sobre las piernas. Hablábamos poco. Un presentimiento indefinido iba, paulatinamente, cubriendo de hierro el corazón, y la sangre restañada de las heridas parecía secarse también en nuestras venas, al soplo de aquella espantosa certidumbre, de aquella seguridad que ambos sentíamos de caminar hacia una decisión absoluta, por encima de la voluntad del hombre» (1944: 213). 
industrial pasada y el punto de vista posapocalíptico, de manera análoga al clásico de Stephen Vincent Benét «By the Waters of Babylon» (1937), una narración inspirada en el bombardeo de Guernica en que se imaginan las exploraciones por un neoprimitivo de una ciudad de Nueva York destruida por armas como las imaginadas por Benítez de Castro, con la diferencia fundamental de que el protagonista del relato norteamericano encabezará en el futuro un proceso de reconstrucción, con una actitud acorde con el optimismo de la potencia americana en ascenso. En Los días están contados, los miembros de la expedición tienen presente que fue allí «donde se firmó el decreto de guerra, [...] el fin de la civilización» (1944: 220), una civilización de violencia iniciada de nuevo por todas las tribus, que han vivido todas sucesos parecidos a la del protagonista. El Mundo (en mayúsculas en el original) ha fracasado una vez más: «[E]l hombre es malo. Esta es la verdad. No hay ley para él» (1944: 226), de manera que la posible solución propuesta de difundir la fe en Dios como impulso ético se rechaza como ilusoria. Igual que el más fuerte manda en los juegos infantiles, es la fuerza la que impera entre los mayores. El reconocimiento del fracaso lleva a consumar el juramento, que no es otro que el de acabar con la semilla del mal, acabando con toda la especie. La batalla entre los de Hachos Regila y los de Almo se prolonga, sin solución de continuidad, con la masacre y el suicidio de los supervivientes. Solo Hachos Regila, que había sido dado por muerto, se despierta a tiempo para asistir a la agonía de su planeta, a la explosión que conduciría su cadáver y su testimonio al nuestro. La catástrofe se describe con gran sobriedad, no exenta de vigor ni de poesía, y sin subrayarse en exceso el carácter simbólico, de justicia poética, de la «inmensa hoguera de purificación» (1944: 241) que engulle el mundo de Alfa Centauri, nuestro espejo. La última línea de la novela indica ese reflejo al culminar la conversación que comenta en el epílogo de la novela los sucesos contados por Brian con la noticia del estallido de la guerra, esto es, de la Segunda Guerra Mundial. Aunque la historia contada por el profesor ni se puede probar ni será creída, queda su valor de analogía para la civilización humana contemporánea, en la que «la fe y el amor van quedando arrinconados, como las pieles y pinturas murales de los hombres primitivos» (1944: 253). Al adelanto técnico no habría correspondido una mejora ética y el conocimiento de las atrocidades cometidas en esos años no podía sino confirmar el pesimismo, en un período en que, de hecho, los días parecían estar contados, aún antes de que la Guerra Fría agitase el espectro de la destrucción atómica.

Pasados los años, sabemos que tan negros presagios no se han cumplido, al menos aún. Ni siquiera la violencia parece ser ahora mayor que entonces. Con todo, la novela de Benítez de Castro sigue siendo válida no solo como obra literaria bien pergeñada y escrita, en la mejor línea de la ficción utópica y del scientific romance. $\mathrm{Su}$ aviso tiene la validez universal que le confiere el hecho de que su arraigo en las circunstancias de la guerra coetánea se combina con el extrañamiento especulativo que se desprende de su ambientación en dos mundos posibles presentes y, a la vez, alejados de aquellas circunstancias, lo que le facilitó esquivar la doble trampa de la propaganda y del reportaje, además de no caer en el espejismo de la defensa o ataque frente a doctrinas sociopolíticas determinadas. El enfoque de Benítez de Castro está en las antípodas del de su primera novela, la que le ha colgado el sambenito de 
escritor fascista. Su humanismo no conoce preferencias partidistas. Es más, es un humanismo que se anula a sí mismo debido a su lucidez. No está claro que a la muerte de Dios tenga que suceder el suicidio de la especie humana como una solución viable a los males de la modernidad, pero Benítez de Castro no recurre al falso consuelo de pensar que cualquier curso utópico alternativo acabaría dando resultados distintos en el mundo real. Sin embargo, el nihilismo de la novela, más melancólico que desesperado, impide también pensar en que dejar las cosas como están sea tampoco una solución que pueda impedir la futura catástrofe provocada por nosotros mismos. Los días están contados es sobre todo una obra profundamente pesimista, como no podía menos de serlo en unos años en los que el ser humano solar, como su equivalente imaginario de Alfa Centauri, estaba dando sobradas muestras de su índole radicalmente violenta, constatación que confiere a la novela su trágica dimensión universal, en el tiempo y en el espacio.

\section{Referencias bibliográficas}

BeníteZ de Castro, Cecilio (1944): Los días están contados. Badalona, Barcelona: Prisma. CAMPAL FERNÁNDEZ, José Luis (2005): «Se ha ocupado el kilómetro 6..., novela de guerra de Cecilio Benítez de Castro». Dicenda 23: 61-70.

CLARKE, Ignatius Frederik (1966): Voices Prophesying War 1763-1984. London, New York, Toronto: Oxford University Press.

MARTíN RodRíGUEZ, Mariano (2013): «Mundos perdidos, paraísos perdidos: ciudad primitiva y utopía imposible en Los que no descienden de Eva (1941), de Luis Antonio de Vega». Ángulo Recto 5, 1: 45-64.

- (2014): «Panorama de la ficción científica y especulativa española moderna y su recepción hasta la guerra civil de 1936». Hélice II, 3: 5-32.

MARTínez CACHERO, José Luis (2009): Liras entre lanzas: Historia de la literatura «nacional» en la Guerra Civil. Madrid: Castalia.

NORA, Eugenio de (1963): La novela española contemporánea (1898-1927), 2. ${ }^{a}$ edición. Madrid: Gredos.

- (1968): La novela española contemporánea (1827-1939), 2. a edición. Madrid: Gredos.

ORNSTEIN, Jacob y CAUSEY, James Y. (1951): «La literatura de hoy: Una década de la novela española contemporánea». Revista Hispánica Moderna 17, 1: 128-135.

RIPOLL SINTES, Blanca (2013): «Lo fantástico en la novela popular española de la primera posguerra. A propósito de dos novelas de Cecilio Benítez de Castro», en David Roas y Ana Casas (eds.): Visiones de lo fantástico en la cultura española (1900-1970), pp. 5967. Benalmádena: e.d.a.

RUYER, Raymond (1950): L'Utopie et les utopies. Paris: Presses Universitaires de France.

VAlbuena PRAT, Ángel (1968): «La fantasía y la acción en Benítez de Castro», en Historia de la literatura española, $8^{\mathrm{a}}$ edición, vol. IV, pp. 803-806. Barcelona: Gustavo Gili. 